\title{
LA PHÚSIS COMO DONADORA DE SENTIDO, ESPACIO Y DERECHO EN LAS OBRAS DE MARTIN HEIDEGGER Y CARL SCHMITT: UN ESTUDIO COMPARATIVO.
}

\author{
THE PHÚSIS AS SOURCE OF SPACE, SENSE AND LAW IN THE WORKS \\ OF MARTIN HEIDEGGER AND CARL SCHMITT: A COMPARATIVE STUDY
}

\author{
Juan Manuel Romero Martínez ${ }^{1}$ \\ Universidad de Granada (España)
}

Recibido: 10-10-2014

Aceptado: 04-02-2015

\begin{abstract}
Resumen: En este artículo trazaremos el hilo conductor entre Schmitt y Heidegger mediante el concepto de phúsis, el brotar emergente desde el que se dona la totalidad de un mundo de sentido, propiciado por lo que Heidegger llamará una mutua pertenencia entre emergencia /phúsis / ser y pensamiento / Da-sein. Si en la obra del filósofo de Messkrich esta apropiación entre phúsis y pensar humano abre el mundo en su totalidad de manera histórica, en la del jurista de Plettenberg, la naturaleza dinámica de la phúsis se trastoca telúrica, donadora de legalidad y ordenamiento del territorio. En este estudio comparativo intentaremos aclarar cómo lo indisponible al ser humano se erige en fuente de legalidad en estos dos autores.
\end{abstract}

Palabras-clave: phúsis, nómos, Ereignis, Derecho, técnica, espacio.

\begin{abstract}
This article will trace the common thread between Schmitt and Heidegger through the concept of phúsis, sprout emerging from which an entire world of meaning is donated, encouraged by what Heidegger called a mutual belonging between emergency / physys / being and thinking /Da-sein. By one side, for the philosopher of Messkrich, the appropiation between phúsis and human
\end{abstract}

[1] (referne101@hotmail.com) Doctorando en la Universidad de Granada, Departamento II de Filosofía, se licenció en la UGR en el año 2010 y completó, en los años sucesivos, un máster en Filosofía Contemporánea (UGR) y otro en Formación del profesorado (UCM). Ha participado en diversos congresos y cursos relacionados con la filosofía política y el problema del nihilismo. Su línea de investigación se centra en la ontología política, en concreto en la relación entre la concepción heideggeriana del Kairós y el decisionismo en la filosofía política de Carl Schmitt. Su última publicación es "Lo inhóspito y lo sublime" en Thémata: Revista de filosofía, $\mathrm{N}^{\circ}$ 46, 2012, págs. 627-634, donde relaciona el concepto de los sublime en Kant, que falta a toda representación posible, y lo indisponible en la obra de Heidegger. 
thinking opens the whole world historically; by the other, in the work of the jurist born in Plettenberg, the dynamic nature of the phúsis turns telluric, donor of space and legality. In this comparative study we will try to clarify how the unavailable stands for humans beings as source of legality.

Key-words: phúsis, elements, Ereignis, Right, technic, space.

\section{Introducción: Schmitt y Heidegger sobre lo indisponible.}

La relación filosófica entre Schmitt y Heidegger, su mutua apropiación que diría este último, tal vez consista en un apriorismo que en el caso del primero atañe al concepto de legitimidad de la autoridad del soberano, tanto en su época decisionista como en la telúrica; mientras para el segundo consiste en aquello que se resiste al sentido y, a la vez, posibilita el sentido mismo. La instancia de lo indisponible se presenta en ambos autores como anterioridad prerreflexiva al establecimiento de una época y, en concreto en el caso de Schmitt, a la ley positiva (Gesetz) de un determinado territorio.

Esta instancia irracional en el ámbito constituyente del Estado se muestra en que, como Hobbes, Schmitt entiende que el soberano está fuera del contrato que ata los poderes de sus súbditos a su persona. Evidentemente el jurista de Plettenberg no es contractualista, sin embargo recoge de Hobbes la inclinación a pensar que el soberano guarda en sí un cierto estado de naturaleza que, tanto trascendental como trascendentemente, lo sitúa más allá de la obediencia a la ley² de la que él es garante.

$\mathrm{El}$ apriorismo al que me refiero se expresa en la creencia por parte de Schmitt de que la condición de posibilidad de la legalidad es la excepción de ésta misma, fundamento que hace legítimo al soberano, el cual deviene alegal para así poder imponer legalidad. En el Schmitt de la etapa decisionista el soberano es quien, para garantizar la "perseveración del ser de un pueblo"3,

[2] Cf. Agamben, G. Homo Sacer: el poder soberano y la nuda vida, I, Ed. Pre-textos, Valencia, 1998, pgs. 54 y sigs.

[3] Schmitt,C. Der Begriff des Politischen (1927), $2^{\text {a }}$ ed. (Hamburg: Hanseatische Verlagsanstalt, 1934) pgs. 8-10: "eine kämpfende und sich durchsetzende Gesamtheit von Menschen". Este párrafo aparece en la versión de 1927 (Hamburgo), pero no en la de 1932 (Berlín), edición de la que se sirve Alianza para su traducción, razón por la que me permito un vertido propio de éste párrafo al español, de manera que se resalte el matiz de conato spinozista que dota Schmitt al texto mediante ese "sich durchsetzende": "una comunidad de hombres (comunidad política, se entiende) que lucha y persevera en sî"; más adelante usará el término latino "perseverare": "das eigene Sein zu wahren, in suo esse perseverare". De esta manera perseverar y preservar quedan ligados en los términos wharen (guardar, mantener, conservar, preservar, cuidar) y durchsetzen (hacer prevalecer). Esta determinación del perseverar es eminentemente ontológica o "existencial" como más adelante comenta el propio Schmitt en la misma obra y, desde la tradición aristotélica y espinocista de la substancia entronca con la Sorge heideggeriana, el cuidado, el procurar por del proyecto en la existencia. La relación que propongo entre wharen, durchsetzen y Sorge es, por supuesto, sincrónica.

THÉMATA. Revista de Filosofía, No51 enero-junio (2015) pp.: 363-382

doi: 10.12795/themata.2015.i51.19 
decide (entscheiden) quién es el enemigo y cuándo ha de declarársele la guerra. Para ello éste suspenderá derechos y garantías en la instauración de un estado de excepción en el caso de que se establezca una situación de guerra real con otro Estado, mediante el que hará uso de la vida y la muerte de todos sus súbditos para garantizar dicha "perseveración de la comunidad política en su ser."

La figura del soberano en Schmitt no está del todo delimitada por el número, tanto una oligarquía como un solo gobernante son válidos con tal de que tengan la capacidad de decidir e imponer una situación excepcional; no obstante, nuestro jurista tiene muy claro que el contexto desde el que debe constituirse el Estado, en el momento en el que escribe, es democrático por lo que el soberano, sean unos pocos o sea uno sólo, debe ser elegido por la voluntad del pueblo; hasta tal punto es esto así que incluso llega a identificar al soberano con el mismo pueblo ${ }^{4}$. Estas consideraciones políticas surgen en el contexto de la democracia parlamentaria de la república de Weimar. Schmitt quiere "rescatar" la democracia del sistema parlamentario liberal por un lado y combatir el positivismo jurídico imperante en la época

Tras su activismo en el partido nacionalsocialista alemán, forzado a apartarse de los centros de poder del régimen y, al término de la guerra, acusado por los aliados en los famosos juicios de Núremberg Schmitt, sumido en una profunda crisis existencial ${ }^{5}$, reconstruiría el concepto de legitimidad de la soberanía de un pueblo en la noción de "nómos de la tierra" que, aparentemente, desplaza al de la lucha para la perseveración de la unidad esencial de una comunidad política. En este nuevo contexto la legalidad surge de la toma de y el trato con la tierra (Landnahme); una concepción que recuerda mucho a la de la Naturaleza de los griegos, la phúsis, en la que la tierra es aquello que se dona desde sí misma, brota y emerge en un movimiento con la que el ser humano debe habérselas. Es en ese "habérselas" donde surge, sin regla previa, la legalidad y la legitimidad de un pueblo soberano.

Tanto la toma de tierra como la decisión del soberano en la excepción de la regla son elementos que se resisten al sentido, opacos y clausurados, no obstante donadores de legalidad ambos. Este juego de clausura en la apertura es lo que nos pone abiertamente en relación con el análisis heideggeriano de la sentencia de Heráclito, phúsis kriptesthai philei, en el que el filósofo de Messkrich va desgranando sutilmente el concepto de alétheia como movimiento dinámico de la Naturaleza el cual al ser producción, presentación, brote de mundo y de sentido, a la vez se oculta y se resiste a todo sentido (kriptesthai). Es por esta razón por la que se dedica en este artículo un apartado a tal análisis.

[4] Cf. Kaufmann, M. ¿Derecho sin reglas? Los principios filosóficos de la teoría del Estado y del derecho en Carl Schmitt, Ed. Alfa, Caracas/Barcelona, 1989, pgs. 7-8.

[5] Cf. Volpi, F, "El poder de los elementos" en Tierra y Mar, una reflexión sobre la historia universal, Trotta, Madrid, 2007, pg. 84.

[6] Der Nomos der Erde se publica en 1950

THÉMATA. Revista de Filosofía, $\mathrm{N}^{\circ} 51$ enero-junio (2015) pp.: 363-382 doi: 10.12795/themata.2015.i51.19 
El concepto de phyisis es el elemento con el que en este trabajo ${ }^{7}$ se liga a los dos autores, ya que ambos han lidiado con él y lo han tenido muy en cuenta para sus consideraciones filosóficas. La indistinción entre nómos y phúsis que en sí guarda el soberano hobbesiano y schmittiano entronca, como hemos comentado antes, con la heterogeneidad de una Naturaleza más allá de toda representación que a su vez se dona en sentido, despliegue de fuerzas y legalidad, tal y como lo expresa la alétheia heideggeriana. Agamben en Homo Sacer $^{8}$ sostiene que, es en la figura del soberano, en la que se dan cita la violencia que irrumpe de la phúsis, esa emergencia del estado de naturaleza que se resiste y el nómos civilizatorio, "umbral de indiferencia entre violencia y ley" que legitima a la figura del soberano. Pero la naturaleza, trastocada en los elementos telúricos del segundo Schmitt, sufre mutaciones espaciales a causa de la técnica, de la misma manera que el modo de responder al brotar de la naturaleza por parte del ser humano abre una era en la que la figura de la verdad es técnica para el segundo Heidegger. Es por esta razón por la que no podemos obviar el análisis que estos dos autores hacen de la phúsis en sus alteraciones por parte de la técnica; el mundo técnico amplia y transforma la ordenación espacial del territorio, de manera que el nómos se hace difuso en sus límites, ya que las fronteras entre Estados y, por lo tanto, el Derecho internacional se hace líquido en el mar y etéreo en el aire. El dominio sobre lo aéreo de la nueva aviación, de las ondas de radio; la hegemonía sobre la mar por los nuevos buques de guerra, por los sumergibles alemanes que provocaron la entrada de Estados Unidos en la Primera Guerra Mundial, son testimonio de que la Tierra se estaba abriendo a un nuevo nómos, una nueva ordenación espacial del territorio de carácter global. De la misma manera Heidegger entiende que, el modo de representación de los entes, se ha transformado en la era de la técnica hasta el punto de no ser ya meras representaciones sino existencias en stock, disponibles para su uso en cualquier momento que lo precise la industria y el consumo: una mutación de lo que la phúsis dona libremente en artículos para resolver contingencias técnicas. En definitiva, para los dos autores, la técnica supone un cambio ontológico del modo de "habérselas" con el movimiento de donación de la Naturaleza.

[7] Es necesario nombrar el magnífico artículo de Patricio Peñalver en la revista Daimon, en el que el autor sugiere la conexión entre Schmitt, Heidegger y el teólogo Barth mediante el concepto de decisión, puesto en boga tras la Primera Guerra Mundial en Alemania por el "renacimiento" del pensamiento de Kierkegaard. Desgraciadamente el artículo aplaza el análisis de esta relación para un futuro escrito que, si existe, aún no tenemos noticia de ello. Yo me he centrado más en los conceptos fundamentales del segundo Schmitt y el segundo Heidegger, en concreto en el juego entre phúsis y nómos, pero es cierto que la relación entre la decisión schmittiana y la resolución heideggeriana es otra magnífica línea de investigación para poner a estos dos autores en comunidad ontológica. Ver: Peñalver, P. "Decisiones, Schmitt, Heidegger, Barth”, Daimon, 13, 1996, pgs 141-166.

[8] Cf. Agamben, G. Homo Sacer: el poder soberano y la nuda vida, I, op.cit, p. 51.

[9] Ídem.

THÉMATA. Revista de Filosofía, Nº51 enero-junio (2015) pp.: 363-382

doi: 10.12795/themata.2015.i51.19 


\section{El ser como phúsis.}

Heidegger nos invita en su análisis acerca de la técnica a remontamos, no ya al asunto de lo técnico desde su representar, desde una coherencia y corrección del concepto con lo técnico, sino desde su esenciar: desde el modo en que viene a la presencia la técnica y muestra en ese movimiento su verdad en tanto que alétheia, en tanto que des-ocultación. Para ahondar en el concepto de verdad como des-ocultación ( $a$-létheia) es necesario esbozar, aunque de manera algo breve, qué concepción tiene este autor de la realidad.

En "Ciencia y Meditación ${ }^{10 "}$ el autor entiende que la realidad es dinámica y actúa como un obrar o estar en obra (érgon). El rasgo fundamental del obrar no descansa según él en el efficere y el efectus de la tradición latina, lo que quiere decir que el obrar no supone llevar a cabo un efecto dentro de las relaciones causales de la Naturaleza; antes bien, el obrar del griego originario es un traer ahí a la plenitud de la presencia.

Phúsis nombra a lo que prevalece como crecimiento de la Naturaleza en ese traer ahí: un producir, hacer de la Naturaleza; por otra parte Hediegger tomará de Aristóteles el término thésis para nombrar la posición, el emplazamiento o situación del producir. Este emplazamiento es el horizonte, el contexto, el campo de juego en el que una determinada figura de la verdad es traída a la presencia en el claro. En el caso que nos concierne para este artículo la thésis es el Gestell, o la estructura de emplazamiento que esencia o posibilita la era de la técnica que, según el filósofo, corresponde a la nuestra. Así ambas thésis y phúsis nombran un obrar, un hacer; nombran lo real en un determinado momento histórico

En "Sobre la esencia y el concepto de la phúsis. Aristóteles, Física B. I" ${ }^{11}$ Heidegger menciona un fragmento de Heráclito en el que se dice que "phúsis kryptesthai filei”, a la Naturaleza le gusta ocultarse. La interpretación de la aserción heracliteana no viene a expresar la dificultad de la exploración y el alcance del núcleo interno de la Naturaleza porque ésta guste de ocultarse sino que, al contrario, propone que el ocultamiento mismo es su esencia. No hay Naturaleza sin ocultamiento, se nos viene a decir. En el movimiento de venir a presencia de la Naturaleza hay otro de ocultación de sí misma.

Finalmente, el movimiento de la puesta en obra de la verdad (alétheia), es éste surgir de la phúsis en el que la cosa, como ente, llega a ser lo que es. El llegar a ser lo que se es (la entelequia aristotélica), es un trabajo de emergencia

[10] Cf. Heidegger, M. "Ciencia y Meditación" en Conferencias y artículos, Ediciones del Serbal, Barcelona, 2001, pgs 36 y sig.

[11] Cf. Heidegger, M., "Sobre la esencia y el concepto de la phúsis. Aristóteles, Física B. I" en, Hitos [Wegmarken], Ed. Alizanza, Madrid, 2000, p. 248.

THÉMATA. Revista de Filosofía, No51 enero-junio (2015) pp.: 363-382

doi: 10.12795/themata.2015.i51.19 
donde lo ente sale a la luz y se constituye como tal en un mundo de sentido.

\section{Ereignis ${ }^{12}$ y Gestell $^{13}$ : el acaecimiento apropiador y el dispositivo de emplazamiento.}

El ser es el acontecimiento de la venida a la presencia de un mundo de sentido que se oculta, simultáneamente, en la misma presentación de dicho mundo de sentido como lo ente. Ahora bien, para que ello pueda tener lugar, ha de permitirle el Dasein su llegada-ocultamiento. Permitírselo es entregarse a la escucha del acontecimiento que es ese ser y, de este modo, dejarlo libre en la comprensión que se está generando en dicha escucha. Por ello en el acontecimiento del ser hay una correspondencia entre existente (Dasein), en cuanto que escucha la llamada del ser; y ser, en la medida en que por mor de dicha escucha cumple su llamada y acaece en pos de la presencia de lo ente. Este acontecer, si lo es en sentido "propio" (eugen), genera una "apropiación" mutua (zusamengehören) entre acontecer y escuchar. En otros términos se ha hablado de una vocación, un llamamiento e incluso una provocación por parte del ser al que el ser humano, en tanto que existente, responde. El momento de coportenencia o mutua apropiación entre ser y humano es un "acaecer propicio", el Ereignis.

Dos son las definiciones que podemos atribuir al Ereignis: en un primer lugar el acaecimiento de apropiación que esencia, esto es, otorga al ser humano su esencia, que consiste justamente en estar a la escucha de la provocación del ser y preparar su aparecer, de la misma manera que el ser lo es sólo, se esencia, en la medida en la que la humanidad dispone o prepara su venida en el claro (Lichtung) en el cual viene a la presencia; por otra parte, el otro aspecto fundamental de este acaecimiento apropiador es el histórico-epocal del ser, ya que éste se manifiesta en muchas figuras a lo largo de la historia de la metafísica (Geschichte): Naturaleza, Dios, espíritu, voluntad y Gestell. ${ }^{14}$ Con esta consideración

[12] Un término técnico que H.Cortés y A. Leyte traducen en Heidegger, M., Identidad y diferencia, Anthropós, Barcelona, 1988, pp. 47, 85-86 como "asir con los ojos" o "llamar con la mirada" pero que en el alemán de calle significa "evento" o "suceso". El sentido de la traducción de Leyte y Cortés trata de volcar el matiz más "originario" que Heidegger escucha en el término. El uso del guion en el término sirve para resaltar el sentido del verbo "eignen" (hacer apropiar) que está contenido en la palabra. Según los dos traductores, es este sentido de "apropiar" el que le interesa a Heidegger y no el de acontecimiento o evento ya que, lo que acontece en el Er-eignis, es eso: una apropiación entre ser y pensar. Por eso, para explicar el término en el texto, sigo las instrucciones de los traductores y me refiero a él como "acaecimiento de apropiación / evento de transpropiación o, incluso, acontecimiento propicio".

[13] Gestell, en su uso cotidiano, significa "armazón", "chasis", "bastidor", "esqueleto", "dispositivo": la estructura física interna de un objeto, comentan los traductores de Heidegger, M., Identidad $y$ diferencia, op.cit., p. 83. Del verbo "stellen": "poner" o "colocar" mientras que el prefijo "Ge-" tiene en alemán el sentido de conjunto o colectivo. Dos sentidos que los traductores tratan de rescatar en el término "com-posición" y que F.Duque traduce como "dispositivo de emplazamiento"

[14] Cf. Escudero, J.A, El lenguaje de Heidegger, diccionario filosófico 1912-1927, Herder, Barce-

THÉMATA. Revista de Filosofía, No51 enero-junio (2015) pp.: 363-382

doi: 10.12795/themata.2015.i51.19 
del ser como acaecimiento histórico de las figuras de la verdad, el filósofo viene a establecer los diferentes modos en los que la metafísica ha fundamentado la totalidad de lo ente de manera estática a lo largo de la historia acontecida del ser (onto-teología). Los diferentes modos de acaecer el ser lo han sido siempre desde la consideración de que cada uno de ellos era el auténtico y definitivo fundamento de lo real, concepción que expresa una noción estática del ser.

\section{En Identidad y Diferencia expone Heidegger:}

"El Er-eignis es sólo lo más próximo de aquella proximidad en la que ya estamos. Pues, qué podría resultarnos más próximo que lo que nos aproxima hacia aquello a lo que pertenecemos, en donde tenemos nuestro lugar, esto es el acontecimiento apropiador (o propicio, o transpropiador 'Er-eignis'). El acontecimiento de transpropiación es el ámbito en sí mismo oscilante, mediante el cual el hombre y el ser se alcanzan el uno al otro en su esencia y adquieren lo que les es esencial al perder las determinaciones que les prestó la metafísica." ${ }^{15}$

Ahora bien ¿qué pasa cuando el acontecer tiene lugar de modo "impropio"? Esto ocurre cuando esa relación de provocación y escucha se ve forzada por la voluntad humana en la creencia de que ella es la dueña y señora del modo en el que el ser acaece. La penúltima figura, la de la voluntad, será la que culmine la historia de la metafísica, ya que supone en su impropiedad el enseñoreamiento del ser humano de todo lo real, por lo que éste se yergue en medida absoluta de todas las cosas y, por lo tanto, de su relación con el ser; ésta es la figura de la verdad que coincide con la crítica heideggeriana a la Voluntad de Poder y al concepto de Über-mensch de Nietzsche. Pero la última figura, la del Gestell, es considerada por Heidegger como postmetafísica, la impropiedad de la metáfora óptica mediante la que el ser humano ordenaba y ponía el mundo en tanto que representación, que es lo que caracteriza a la metafísica desde la modernidad, ha llegado a su fin al deslindarse la esencia de la técnica de la voluntad humana y hacerse aquélla no-humana, consideración que Heidegger ha experimentado en el terror atómico, como más tarde veremos.

Para entender mejor en qué consiste el Ereignis, no debemos pasar por alto el hecho de que Heidegger lo define como "mismidad": en Identidad y Diferencia nuestro autor establece una clara distinción entre el principio de identidad que, según él, es lo que subordina toda la metafísica occidental; y lo uno como mismidad, que expresa Parménides en aquel famoso verso: "Lo mismo es el ser que el pensar". El principio de identidad deriva originariamente de esta mismidad en la que se copertenecen mutuamente ser y pensar (ser y humano); esa unidad a la que el autor denomina Ereignis.

"La palabra Ereignis ya no significa aquí lo que en otros lugares denominamos como algún tipo de acontecimiento, algo que sucede. La palabra se utiliza ahora como singulare tantum. Lo que nombra acontece sólo en la unidad, esto es, ni siquiera en un número, sino

lona, 2009, p. 79 .

[15] Cf. Heidegger, M., Identidad y diferencia, op.cit, p. 89.

THÉMATA. Revista de Filosofía, $\mathrm{N}^{\circ} 51$ enero-junio (2015) pp.: 363-382 doi: 10.12795/themata.2015.i51.19 
de modo único." ${ }^{16}$

Esta es la unidad de la mismidad que constituye el pliegue (Zwiefalt), ese entre donde ser y pensar se hacen uno. Si la forma propia de acaecer en mismidad es Ereignis; la impropia es Gestell ; sin embargo esta última, pese a su impropiedad, no deja de ser demanda del $\operatorname{ser}^{17}$ ya que, lo que el ser humano entiende como dominio técnico de lo real, es el modo en el que el ser ha provocado al Dasein en su destinar; así de ambigua es la figura del acaecer de la verdad. La condición que nos muestra Heidegger del Gestell en Identidad y diferencia es inhumana. La técnica tiene sus propios procederes, independientes de los requerimientos humanos, cosa que podemos atestiguar en el hecho de que el poder atómico puede escaparse del control de las manos, demasiado humanas, de los hombres. Así es como se muestra la verdad de la era técnica, como la indisponibilidad no humana del ser para con hombre ${ }^{18}$.

\section{La posición de Heidegger respecto a la técnica.}

En una primera lectura de La pregunta por la técnica nos encontramos ante una aparente ambigüedad entre el peligro y lo que salva. ¿Cómo es posible que en aquellos versos de Hölderlin encontremos, con Heidegger, la clave para entender la esencia de lo que constituye lo técnico?

"Pero donde hay peligro, crece

también lo que salva." ${ }^{19}$

Tres términos resaltan en estos versos: peligro, crecimiento y salvación. Aquello en lo que, aparentemente consiste el peligro, es en que ese modo técnico de despejamiento que es la era de la técnica en la que vivimos, termine por colapsar toda otra forma de despejar el ser; toda otra forma de acontecer y que por ello, la humanidad enseñoreándose de la Naturaleza, no pueda ya nunca más que ser provocada a emplazarla a modo de existencias, lo que supondría una lesión de la misma esencia de lo humano, si la entendemos con Heidegger, como destinada a la apertura futurible de lo que acaece. Pero deberíamos preguntarnos si para nuestro filósofo es posible descentrar al hombre de su

[16] Heidegger, M., Identidad y diferencia, op.cit, p.87

[17] Cf. Heidegger, M. Identidad y diferencia, op.cit, pp. 87-88 "Lo que experimentamos en la composición (Gestell) como constelación entre ser-hombre a través del mundo técnico, es sólo el preludio de lo que se llama acontecimiento de apropiación. Pero el Gestell no se queda precisamente detenido en su preludio, pues en el acaecimiento apropiador habla la posibilidad de sobre-ponerse al mero dominio de la composición para llegar a un acontecer más originario".

[18] Cf. Ibíd. pp. 79-81

[19] Cf. Heidegger, M., "La pregunta por la técnica" en Conferencias y artículos, op.cit., p. 31

THÉMATA. Revista de Filosofía, No51 enero-junio (2015) pp.: 363-382

doi: 10.12795/themata.2015.i51.19 
esencia. ¿Puede perder el ser humano su definición por excelencia como vecino y pastor de lo que acaece? Para el filósofo de Messkrich es absurdo pensarlo, la humanidad no puede dejar de ser a una con la apertura misma porque ontológicamente está destinada a ella ${ }^{20}$; ésta sólo lo es si hay apertura, y la apertura solo puede darse si hay ser humano. Mientras haya humanidad habrá apertura aunque parezca colapsada en algún momento epocal. No sólo eso sino que, al fin y al cabo, la estructura de emplazamiento (Gestell), el modo en que, como hemos visto antes, esencia la técnica en tanto que provocar al humano para hacer de la Naturaleza existencias almacenables, es en sí misma un acaecer. El Gestell, el modo demandado en apropiación con el humano, mediante el que se da el acaecer del ser en la era de la técnica, es también alétheia, es también un juego de venida a presencia y ocultación, que ha provocado a la humanidad a entenderse a sí misma, de manera ilusoria, como dueña y señora de su relación con la Naturaleza; como la que verdadera y adecuadamente dispone la técnica a sus propios fines. Y es así que "crece la salvación" porque el peligro, el Gestell, es crecimiento: es emergencia del ser que reclama un determinado acaecer. De manera que, lo que Heidegger entiende por salvación, es esto, que la estructura de emplazamiento (Gestell) es también un acaecimiento apropiador que se dona desde sí, en él se encuentra obrando la Naturaleza como phúsis. La salvación supone volver a perdurar en esta verdad del ser como puesta en obra, no como mera adecuación o coherencia, sino en el desvelamiento y velamiento de la alétheia. El acaecer es siempre proyectante, advoca hacia futuribles, modos nuevos de darse, pero el modo técnico de lo real muestra en sí una autonomía, un desde sí, en el que el ser humano tiene la oportunidad de vislumbrar que, la manera originaria y propia de acaecer con él, ha sido olvidada; el ser en su retracción siempre es olvido, porque su darse más propio, el Ereignis, es virtual, lo que significa que lo propio y originario siempre tiene que acaecer de una manera distinta a él, en la diferencia, en la heterogeneidad de las figuras epocales de la verdad. El peligro del colapso al que nos hemos referido antes es olvidar para siempre el olvido mismo del ser.

\section{Heidegger y Schmitt respecto a la técnica: nómos y Ereignis.}

\subsection{Phúsis y nómos de la Tierra: espacialidad ontológica y donación de legalidad.}

Según el jurista Carl Schmitt la tierra es la madre del Derecho. Ésta

[20] Cf. Pöggeler, O., El camino del pensar de Martin Heidegger, Alianza Editorial, Madrid, 1993, p. 267: "lo que salva no se halla fuera de la técnica, sino que se enraíza y fructifica en la esencia de ésta. El hombre no alcanzará nunca aquello que salva mientras se limite a impulsar emprendedoramente la técnica a ciegas, ni tampoco mientras la condene como obra diabólica, sino que sólo lo alcanzará cuando torne a hospedarse en su esencia"

THÉMATA. Revista de Filosofía, №51 enero-junio (2015) pp.: 363-382

doi: 10.12795/themata.2015.i51.19 
otorga la medida, el nómos, de manera que contiene el Derecho, la legitimidad en sí misma y la ofrece como donación y recompensa al esfuerzo del trabajo. Entre el trabajador del campo y la tierra misma hay una relación de copertenecia que permite surgir desde lo oculto -que es la tierra- su secreta ley. El trabajador y la tierra se convocan y corresponden en la apertura de la legitimidad de un nómos, lo que sería apertura de un mundo de sentido desde la posición de Heidegger. Este surgir, crecer y donar de la medida, del nómos, puede ser interpretado como phúsis recibida en tanto que ley que se revela en la ordenación (Ordung) política y social del territorio de un pueblo ${ }^{21}$. Pero la ordenación lo es siempre por mor de la tierra y la línea divisoria del suelo, mediante la demarcación espacial y originaria del territorio; no está mediada por ley alguna y, sin embargo, es condición de posibilidad de cualquier ley positiva. ${ }^{22}$

Nos comenta Schmitt, tanto en Tierra y Mar como en El nómos de la tierra, que el nómos se hizo global gracias a los grandes imperios marítimos por los que el reparto y ordenación del mundo se extendieron de la tierra a los mares y océanos. Sin embargo el mar, que en su momento desafío a la tierra al cuestionar la delimitación de fronteras y el Derecho de Gentes, ha devenido gracias a la técnica un espacio a habitar mediante los medios de comunicación e información que, en una era global, radian la superficie del globo terrestre con independencia de su carácter seco o húmedo. Han desaparecido, con esta nueva era, los fundamentos de conquista inglesa del océano y la tierra hasta ahora existentes. Ha acaecido un nuevo nómos a causa de una revolución de carácter ontológicamente espacial que alcanza dimensiones planetarias ${ }^{23}$.

Ya no habitamos de la misma manera la tierra como cuando se alumbró el Derecho de Gentes europeo tras las guerras de religión. La técnica ha realizado una revolución de los conceptos espaciales desde la Gran Guerra, en la que se conquista un tercer elemento, el aire, mediante la aparición del aeroplano, que se añade a la mar y la tierra. ${ }^{24} \mathrm{El}$ nuevo nómos se encuentra "emplazado" (Heidegger) o "reclamado" (Schmitt) por las nuevas relaciones entre los hombres y su modo de corresponder a la tierra, el mar y el aire. Somos ya

[21] Cf. Schmitt, C. El nomos de la tierra en el Derecho de Gentes del "Ius publicum europaeum", Ed. Comares, Granada, 2002. Pág. 36: "En la toma de tierra, en la fundación de una ciudad o de una colonia se revela el nómos con el que una estirpe o un grupo o un pueblo se hace sedentario, es decir se establece históricamente y convierte un trozo de tierra en el campo de fuerzas de una ordenación. Sólo en relación con un nómos de esta índole, y no con cualquier disposición o aún con una norma separada de una físis concreta, tienen un sentido las frases frecuentemente citadas de PÍNDARO o HERÁCLITO...]"

[22] Ibíd., p. 6:” [...] De este modo surge una primera medida que contiene en sí todas las ulteriores medidas [...]. Todas las ulteriores relaciones jurídicas con el suelo del territorio dividido [...] están determinadas a partir de esta medida primitiva, y todo juicio ontónomo que sea adecuado se origina en el suelo."

[23] Cf. Schmitt, C. Tierra y mar, Ed. Trotta, Madrid, 2009, pp. 48-49.

[24] Ibíd., p. 80 y sig.

THÉMATA. Revista de Filosofía, No51 enero-junio (2015) pp.: 363-382

doi: 10.12795/themata.2015.i51.19 
en un mundo de sentido que ha clausurado el viejo nómos anterior y está otorgando una nueva medida y orden, un nueva ordenación territorial del mundo. Comenta Schmitt, a colación de una paráfrasis de Heidegger ${ }^{25}$, que el espacio no es ya una profundidad vacía de todo contenido imaginable, sino que se ha convertido en un lugar donde despliega el hombre sus fuerzas y energías; en un lugar donde habitar, en definitiva. Al invocar el epígrafe veinticuatro de Ser y Tiempo, Schmitt nos ha remitido de nuevo al concepto de "ser-en-el-mundo" como constitutivo del Dasein, un estar ya previo "en" el mundo que no sólo hace del espacio el lugar del despliegue de fuerzas, sino que la espacialidad habitable que supone este ser-en-el-mundo es apertura misma del hombre como Dasein. Es por eso que, desde este modo de entender el espacio, podemos ahora comprender que tanto el mar como la tierra y el aire son la phúsis (Naturaleza) que se dona al hombre, de modo que pueda hacerse espacial y temporal constitutiva y ontológicamente y que, el modo en que la esencia de la técnica emplaza al ser humano a habérselas con la phúsis, ha transformado el habitar mismo de los elementos y la manera en que se abre el mundo en la espacialidad y temporalidad. El mundo sigue siendo poéticamente habitado, pero lo óntico de lo tecnológico, el aparato (el aeroplano, las ondas de radio, la bomba atómica) y no ya sólo la esencia de lo técnico [Gestell] como demanda, ha modificado el ámbito de lo ontológico. Una retroalimentación desde lo óntico a lo ontológico no explicitada claramente en Heidegger, que en Schmitt es más que evidente.

\subsection{El nuevo nómos como neutralización del centro de gravedad de un espacio: la técnica.}

Para Schmitt el ser humano tiene una determinada conciencia del espacio que se encuentra sujeta a cambios históricos. La diversidad de formas de vida, de modos de habitar el espacio, corresponde a la multiplicidad de mundos de sentido y de espacios de despliegue de fuerzas. El gran peligro de la época consiste en que la coexistencia de diferentes mundos de sentido "descomponga y saque de quicio el gran problema" ${ }^{26}$. Las fuerzas históricas impulsan nuevas incorporaciones de tierra y mar al ámbito espacial de la existencia humana y, gracias a estas fuerzas, surge así un nuevo nómos que se experimenta como nuevas ordenaciones de la tierra, el mar y el aire; de la vida de nuevos pueblos que hace cambiar la estructura misma del concepto de espacio. En esto consiste una revolución espacial.

Las revoluciones espaciales suponen desplazamientos del centro de gra-

[25] Cf. Heidegger, M., Ser y Tiempo, op.cit., pág.132:"El espacio no está en el sujeto, ni el mundo está en el espacio. El espacio está, más bien, 'en' el mundo, en la medida en que el ser-en-el-mundo, constitutivo del Dasein, ha abierto el espacio."

[26] Schmitt, C., Tierra y Mar, op. cit., p. 48.

THÉMATA. Revista de Filosofía, $\mathrm{N}^{\circ} 51$ enero-junio (2015) pp.: 363-382

doi: 10.12795/themata.2015.i51.19 
vedad metafísico que constituye una época ${ }^{27}$. Así, los conceptos filosóficos, jurídicos, históricos que elaboran las diversas generaciones sólo resultan comprensibles a partir de desplazamientos desde el núcleo central. Dichos movimientos de desplazamiento de espacios habitables de sentido no se dan conforme a una ley teleológica, tampoco suponen una línea ascendente e ininterrumpida de progreso, de la misma manera que para Heidegger no hay mejores mundos de sentido que otros. Para Schmitt, pese a que la época en concreto esté marcada por un núcleo de gravedad, es posible que en ella aún coexistan vestigios de otras metafísicas imperantes en épocas posteriores, que han quedado como problemáticas de segundo orden sólo resolubles desde el cuestionamiento resaltado por el núcleo actual. ${ }^{28}$

Sin embargo, según el jurista, hemos estado asistiendo a una etapa de neutralización del centro de gravedad desde el intento de poner fin a las guerras de religión en Europa, mediante el paso de la teología al pensamiento científico racional del siglo XVII, hasta la época de la técnica como paradigma de la pura neutralización. Dichas neutralizaciones han tenido como objetivo conseguir unos presupuestos mínimos de convivencia sobre la base de un nuevo poder central. Ahora, en la era de la "mundialización" la técnica ha devenido un suelo firme, absolutamente neutral, que evita cualquier otro intento de descentralización. ${ }^{29}$

La técnica goza de un extraño estatuto de neutralidad: puede ser tanto reaccionaria como revolucionaria, de sus principios y puntos de vista no se hacen preguntas ni respuestas políticas. De la mera técnica no es posible extraer un concepto de progreso cultural ni espiritual, ella misma no es más que un instrumento en manos de quien detente el poder. En sí, según Schmitt, no es más que fe en las probabilidades ilimitadas de modificación de la Naturaleza y del hombre mismo en el más acá (una "metafísica activista", como la llama el autor); lo que espiritualiza la técnica es la creencia en que la técnica despolitiza (neutraliza) en favor de una supuesta paz universal. Nada más lejos, la técnica, mediante su efectividad no puede hacer más que aumentar la paz o la guerra, ambas cosas por igual. Es por esto por lo que Schmitt se plantea que el centro de gravedad de la existencia humana no puede ser un mero dominio neutral, la técnica no puede ser sólo mecanicismo como oposición a lo orgánico: hay espíritu en la técnica y, paradójicamente, es la fe en la neutralización espiritual ${ }^{30}$.

[27] Cf. Schmitt, C., "La era de las neutralizaciones y las despolitizaciones" en El concepto de lo político, Alianza Editorial, Madrid, 2009, pp. 109 y sigs.

[28] Ibíd, p. 113: "Cuando un cierto ámbito ha pasado a ocupar una posición central, los problemas de los demás dominios son resueltos a partir de él y obtienen a lo sumo la calificación de problemas de segundo orden, cuya solución vendrá sola con tal de que se resuelvan los problemas del ámbito central"

[29] Ibíd, p. 117.

[30] Ibíd, p. 122: "Pues la vida no lucha contra la muerte, ni el espíritu contra la falta de él. El

THÉMATA. Revista de Filosofía, Nº51 enero-junio (2015) pp.: 363-382

doi: 10.12795/themata.2015.i51.19 
Como vemos, ni Schmitt ni Heidegger pueden jamás considerar que un espacio de sentido colapse en la neutralización de lo ontológico en favor del imperio de lo meramente presente. No es casualidad que ambos autores utilicen versos de Hölderlin ${ }^{31}$ para recalcar la inevitabilidad del insistir ontológico como marco apriorístico y posibilitador, en el primero de la medida que la tierra otorga como legalidad; y en el segundo del acaecer del sentido. Ya sea en una técnica neutralizadora de toda espiritualidad, la medida siempre pugnará por establecerse "en un saber íntegro donde nace el orden de las cosas humanas"; ya sea en un acaecer técnico, que esencialmente insiste en agotarse en su propia apertura de sentido, que emplaza todo lo que hay como mera existencia a disposición del reinado del hombre sobre el mundo, pero que no deja de ser, aún en su "neutralidad espiritual", el modo ontológico del acaecer más allá de la historia de la metafísica ${ }^{32}$. Tanto para Schmitt como para Heidegger la esencia de la técnica, su "espiritualidad", es la que determina la totalidad de lo ente en general como técnico. Una totalidad que, paradójicamente, niega su carácter de "acaecimiento" y de "metafísica". El mundo técnico se da como agotado ya en su propia "neutralización", no deja resquicio alguno en su saturación para la libertad que es su propio acaecer. Un acaecer que, pese a ser técnico, es salvación por el mismo hecho de acaecer libremente para poder dar lugar a futuros modos de donar nuevos mundos de sentido y nuevos nomoi ${ }^{33}$, nuevas ordenaciones-.

\section{Schmitt y Heidegger: políticas onto-pastoriles y enemistades tecnológicas.}

En el apartado anterior sobre Schmitt y la técnica, hemos aludido a la crítica que éste hace a la neutralidad tecnológica como supuesta neutralizadora de los conflictos que constituyen lo político. Una crítica que ambos, el ju-

espíritu lucha contra el espíritu, la vida contra la vida, y es la fuerza de un saber íntegro de donde nace el orden de las cosas humanas"

[31] En Schmitt, C., Tierra y Mar, op.cit., el autor cita del poema "Der Wanderer" [El viajero] de Hölderlin la siguiente estrofa: "También aquí hay dioses y aquí reinan / grande es su medida."; por otra parte es célebre ya la cita de Heidegger en "La pregunta por la técnica" de otro poema de Hölderlin, "Patmos": "Pero donde hay peligro, crece / también lo que salva" (ver supra, nota 30)

[32] Cf. Heidegger, M., "La pregunta por la técnica", op.cit, p. 30: "En segundo lugar, la estructura de emplazamiento, por su parte, acaece de un modo propicio en lo otorgante que - hasta ahora de un modo no experienciado, pero en el futuro quizá de un modo más experienciado- hace durar al hombre en el ser puesto en uso para el acaecer de la verdad de la esencia de la verdad. De este modo viene a comparecer el emerger de lo que salva"

[33] Cf. Schmitt, C., Tierra y Mar, op. cit., pág. 81: "En su lugar, un nuevo nomos de nuestro planeta surge incontenible e inevitable [...]. Por eso, muchos ven sólo desorden sin sentido donde en realidad un nuevo sentido está luchando por lograr un nuevo orden. “

THÉMATA. Revista de Filosofía, $\mathrm{N}^{\circ} 51$ enero-junio (2015) pp.: 363-382

doi: 10.12795/themata.2015.i51.19 
rista y el filósofo, comparten: la técnica no será el lugar de salvación y progreso humano que se proponía en el imaginario colectivo de los años de entre-guerra y de post-guerra, no neutralizará jamás el conflicto sino que, muy al contrario puede ser la fuente de enemistades. No obstante, pese a las similitudes que hemos trazado mediante los concepto de phúsis y "técnica" entre ambos es justo aquí, en la manera de entender políticamente el carácter de lo técnico, donde se revela una variante ontológica de fondo: Schmitt bascula entre una ontología de la fuerza de inspiración nietzscheana y un concepto ontológico de la tierra y el espacio afines a Heidegger; mientras que en éste último aún está presente una ontología del sentido de referencias claramente fenomenológicas; respecto a lo político, como bien ha expuesto Villacañas ${ }^{34}$, el Martin de los cincuenta, el de La pregunta por la técnica, apela a una no instrumentalización de lo técnico, de manera que la cuestión acerca de la esencia técnica no se deslice bajo asuntos concernientes al aseguramiento, gestión y cálculo de la misma; sin embargo, el Schmitt de los años veinte y treinta, el de Catolicismo romano y forma politica $^{35}$ y La era de las neutralizaciones y las despolitizaciones entiende que, al ser la técnica un problema fundamental de la época, agrupa en torno a ella bandos en liza, enemistados por el aprovechamiento de sus potencialidades situación que, como es sabido, constituye el concepto de lo político para el jurista. Además, la hegemonía de la técnica como fuente de conflictos y problema fundamental de la época, es vigente hasta que se configure otra disposición diferente de fuerzas enemigas, que propongan un nuevo nómos y nuevo problema fundamental; concepción ésta tan cara Nietzsche.

Dos son entonces las diferencias fundamentales que encontramos entre estos autores: en primer lugar la divergencia entre ontologías a causa de una asunción de Nietzsche por parte del jurista y una crítica del mismo por parte de filósofo; en segundo lugar la instrumentalización, inherente a lo político, de la técnica por el primero, contrapuesta a la contemplación extática de la esencia de lo técnico, que inhibe la intervención dominante de la voluntad humana. Para Heidegger Schmitt, pese a su afinidad ontológica respecto a lo que se esconde y lo que es indisponible, aún seguiría preso de la metafísica de la Voluntad de Poder. Al menos es así como lo piensa Villacañas, en un esfuerzo más que notable por realizar entre los dos autores un chorismos político y ontológico irreconciliable.

Otro autor muy conocido, Sloterdijk, también ha incidido en ese momento heideggeriano de la serenidad contemplativa del pastor del ser, no ya desde el ámbito de la neutralización política, sino desde las bondades inhibi-

[34] Cf. Villacañas, J.L., Poder y conflicto, ensayos sobre Carl Schmitt, Biblioteca Nueva, Madrid, 2008, pp. 79-103.

[35] Cf. Schmitt, C., Römischer Katholizismus und politische Form, Gottasche Buchlandlung Nadifolger GmbH, Sutgart, 1923, (Catolicismo romano y forma política, Tr. Campderrich Bravo, R., Tecnos, Madrid, 2011).

THÉMATA. Revista de Filosofía, No51 enero-junio (2015) pp.: 363-382

doi: 10.12795/themata.2015.i51.19 
doras de la escucha. Para el de Karlsruhe el proyecto político de los "onto-pastores" es algo que no se encuentra muy definido en la obra de Heidegger no obstante, piensa éste que sin ser consciente de ello, el autor de Gelassenheit continúa más allá del humanismo la empresa de domesticación de la violencia, la cría y la selección del ser humano. En definitiva, acusa a Heidegger de no haber tenido en cuenta la inclinación inherente de la humanidad a hacer del claro del ser un "campo de batalla de la selección y la decisión" ${ }^{6}$. Sloterdijk señala que el filósofo no ha tomado en cuenta la historia natural y cultural (la hominización y humanización) en la construcción del claro como lugar de despejamiento del ser ${ }^{37}$. Esto supone dos puntos muy importantes en la crítica de Sloterdijk: en primer lugar, que el claro del ser es una construcción "antropotécnica" con una historia biológica y cultural ya que, el lenguaje, que es "la casa del ser" según el de Messkrich, es una herramienta humana y humanizadora con la que se han fabricado el claro mismo y los utensilios usados para ello. Son estos el producto de una singular condición biológica del homo sapiens sapiens, la "neotenia evolutiva" ${ }^{38}$ : venir al mundo prematuramente es lo que le confiere al ser humano la capacidad de ser-en-el-mundo. El fracaso animal del ser humano hace a éste indeterminado y, por lo tanto, un ser-ahí excéntrico abierto al mundo, en cercanía vecinal, gracias a la herramienta del lenguaje, con la casa del ser; el segundo punto de la crítica engarza con el primero ya que, una vez situados el claro y al ser humano antropológica y biológicamente, no es posible ya entender una sociedad pacífica de "constructores de casas" y vecinos del ser. Inevitablemente, según Sloterdijk, las ciudades y los imperios construidos competirán los unos con los otros para imponer la decisión sobre cuál es la mejor manera de habitar junto al ser, lo que supone decidir sobre cuál será la técnica imperante para la mejora del ser humano ${ }^{39}$. El campo de fuerzas en liza de la Voluntad de Poder y el decisionismo de Schmitt son influencias más que evidentes en esta vuelta de tuerca antropo-biológica del autor de las Normas para el parque humano.

\section{El fino oído de Derrida.}

La única carta publicada y conocida ${ }^{40}$ entre Heidegger y Schmitt data del 22 de agosto de 1933, en ella el filósofo agradece al jurista el envío de la

[36] Sloterdijk, P., Normas para el parque humano, Siruela, Madrid, 2000, p. 60

[37] Cf. Ibíd., p.54.

[38] Ídem.

[39] Ibíd, p.60.

[40] Faye, E., La introducción del nazismo en la filosofía, Akal, 2009, pp.258-260. Asombra lo capcioso del título; no obstante el texto está bien documentado.

THÉMATA. Revista de Filosofía, Nº51 enero-junio (2015) pp.: 363-382

doi: 10.12795/themata.2015.i51.19 
tercera edición de El concepto de lo político ${ }^{41}$. Allí Heidegger, además de instar a Schmitt a participar en la reconstrucción de la Facultad de Derecho, esto es, en la aplicación del Führerprinzip ${ }^{42}$ en tal institución, reconoce su aprecio por transcribir completo el fragmento 53 de Heráclito al mantener "basileys" en "Polémos panton men patér esti, panton de basileys, kai tous men theous edeixe tous de anthropous, tous men doulous epoiese tous de eleutheros". El lugar donde Schmitt cita este fragmento es un misterio, no se tiene constancia de ello ${ }^{43}$.

De cualquier manera, lo que aquí nos interesa es, con Derrida, dilucidar aquello que oye Heidegger tanto en el polémos como en el basileys de este fragmento de Heráclito. En El oído de Heidegger se nos pone ante la paradoja del sentido que el filósofo da al lógos heraclíteo tanto en 1935, en los seminarios que darán lugar a Qué es metafísica, donde el término en cuestión se identifica con el Kampf alemán (lucha); como veinte años más tarde, en 1955, en la Introducción a la metafísica, donde el de Messkrich lo asimila a la "amistad misma" ". Lógos es Kampf en 1935 y philía (amistad) en 1955 para el mismo autor. ¿Cómo es posible? En el discurso para la toma de posesión del rectorado de la universidad de Friburgo de 1933, La autoafrimación de la universidad alemana $^{45}$, redactado dos años antes que los seminarios de ¿Qué es metafísica?, la palabra Kampf aparece con fuerza, de tal manera que impregna y vertebra todo el texto ${ }^{46}$. Aquí el sentido de Kampf es el de reunión de la universidad alemana en una sola "fuerza que marca"47 (prägende Karft); la fuerza de la "lucha" que se institucionaliza en tres servicios obligatorios (Bindungen) que vinculan el pueblo "al destino del Estado alemán en una misión espiritual”48. De modo que la reunión del ser alemán es una fuerza que marca en el sentido de lucha y ésta, la lucha (Kampf), es una "fuerza de reunión". Ya no parece en 1933 y 1935 la posición de Heidegger tan alejada de la del Kampf de Schmitt como condición de posibilidad existencial de lo político: la lucha reúne al pueblo en la esencia de un Estado para una misión política y espiritual. No obstante aquí Heidegger no quiere dar a Kampf el sentido de guerra, al menos no solamente. A mi entender la fuerza que marca para la lucha tiene las determinaciones

[41] La carta se encuentra publicada y traducida al inglés por la revista Télos, número especial sobre Carl Schmitt, verano de 1987, p.132.

[42] Principio de autoridad en el que se implanta el sistema de mando del ejército a cualquier institución civil, en este caso concreto la universidad, mediante el que se confiere al rector poderes especiales sobre la comunidad académica.

[43] Ídem.

[44] Derrida, J., Políticas de la amistad, seguido del oído de Heidegger, Trotta, Madrid,1998, p.388.

[45] Heidegger, M. La autoafirmación de la universidad alemana. El rectorado (estudio preliminar, traducción y notas de Ramón Rodríguez), Tecnos, Madrid, 2009.

[46] Derrida, J., Políticas de la amistad, seguido del oído de Heidegger, op. cit, p. 389.

[47] Ídem.

[48] Ídem.

THÉMATA. Revista de Filosofía, Nº51 enero-junio (2015) pp.: 363-382

doi: 10.12795/themata.2015.i51.19 
ontológicas de la "Voluntad de Poder" nietzscheana, en tanto que signo afirmador en la catalización de un campo de fuerzas diferencial ${ }^{49}$. En los textos de este período somos testigos de una acentuación de la influencia de Nietzsche y Schmitt en el pensamiento de Heidegger ${ }^{50}$, como ha afirmado Villacañas en sus ensayos sobre Carl Schmitt. Esto último parece sutilmente expresado en, o es lo que podría desprenderse de, el análisis de Derrida .

El Kampf como la fuerza de reunión, dice Derrida ${ }^{51}$, anuncia lo que en Introducción a la metafísica será "Pólemos (Kampf) und Lógos sin dasselbe", que "Pólemos y Lógos son lo mismo"; donde el primero no mienta una guerra en sentido literal sino un "batirse" con el otro en el "debate". Esto es, según Derridá, lo que oye Heidegger en la traducción de polémos: no se trata de una disociación de la unidad, sino de que la lucha es la que la constituye, de ahí que polémos y lógos sean lo mismo. Así que, en el discurso del rectorado la lucha como Kampf reunía los deberes del pueblo para la esencia de lo alemán y, en concreto, mantiene una oposición abierta entre alumnado y profesorado; un "mantener" éste escuchado como ser capaz de soportar en armonía la tensión entre oponentes, sostener la reunión de fuerzas en oposición, no obstante, armónicas entre sí. Mantenimiento y oposición es lo que logra este determinado Kampf, cosa que arranca un comentario a Derrida sobre la cercanía de Hiedegger con Schmitt, para quien el grupo accede a lo político y al Estado gracias al mantenimiento de una oposición que puede aniquilarlo existencialmente, tal que un ser-para-la-muerte. ${ }^{52}$ El philéin de 1955 en ¿Qué es metafísica? se copertenece con el polémos en que lo erótico de la pregunta filosófica respecto al ser, que es al fin y al cabo la misión de la universidad, se mantiene en una tensión, duelo o batida. ${ }^{53}$ Pero debemos hilar fino en estas consideraciones ya que, como se ha dicho antes, Kampf no designa guerra sino que, en una teología del conflicto refiere, como el polémos del fragmento de Heráclito, al origen: esta liza está antes de los hombres, de los dioses y del philéin mismo porque es originaria. Aquí se encuentra la auténtica separación entre ambos autores. También la guerra en Schmitt tiene un sentido "teo-antropolemológico" ${ }^{4}$, ya que se encuentra en el origen mitológico de la fundación del Estado pero aun así, para el jurista, es necesario que devenga posibilidad real, un télos de la intensidad máxima del conflicto, que constituya la agrupación entre amigos y enemigos, de manera que pueda legitimarse el nómos en la phúsis del soberano.

Finalmente, para cerrar el hilo argumental de todo este artículo, debe-

[49] Cf. Deleuze, Nietzsche y la filosofía, Anagrama, 1998, pp. 61-64 y 73-77.

[50] Cf. Villacañas, J.L., Poder y conflicto, ensayos sobre Carl Schmitt, op. cit., p.80 y sigs.

[51] Derrida, J., Políticas de la amistad, seguido del oído de Heidegger, op. cit, p. 389.

[52] Derrida, J., Políticas de la amistad, seguido del oído de Heidegger, op. cit, pp.390 y 393.

[53] Cf. Ibíd, p.394.

[54] Cf. Ibíd, p.398.

THÉMATA. Revista de Filosofía, №51 enero-junio (2015) pp.: 363-382

doi: 10.12795/themata.2015.i51.19 
mos saltar de nuevo al origen del mismo para traer su esencia a nuestra presencia. ¿Por qué Heidegger otorga tanta importancia al "basileys" del fragmento 53 de Heráclito? Si seguimos a Derrida en su recorrido, advertiremos que el filósofo de Messkrich no oye en "basileys" "el rey", como sería su traducción habitual, sino más bien "Herren" (amo o señor), en oposición al griego "doúlous" y al alemán "Knechte" (esclavos): es decir que el "basileys" nombra "lo libre" 55. El Kampf sería lo libre porque es amo de sí mismo, no se debe a la voluntad de otros para ser; se trata de una libre donación del conflicto como acorde desacuerdo que se mantiene abierto. Esa libre oposición del Kampf ya hemos visto que instituye y no se opone al nómos, tanto en Heidegger como Schmitt; esa libre oposición se dona desde sí, desde lo telúrico, desde lo opaco, desde lo indisponible para posibilitar el ordenamiento territorial o el acaecer de sentido: el Kampf no es ni más ni menos que la phúsis.

Las conclusiones del análisis derridiano alcanzan consideraciones acerca del concepto de soberano de Schmitt, Hobbes y Rousseau en el que aquel, al ser la fuerza que instituye y la institución misma (phúsis), no pertenece a eso mismo que instituye; en todo ello resuena lejana la marejada de una ontología heideggeriana de la retracción del fundamento. Este tema lo hemos insinuado en la introducción mediante el pensamiento de Agamben; sin embargo no es el asunto principal de este artículo que, más que un ensayo sobre la ontológica paradoja de la soberanía, pretende ser un estudio de lejanías y cercanías entre nuestros dos principales autores. Tal cuestión queda emplazada para futuras consideraciones. Lo que importa aquí es haber intentado mostrar la ambigüedad en el copertenecerse del jurista y el filósofo, sobre todo en lo tocante a sus ontologías de fondo, la cuales basculan en hermandad entre la fuerza y el sentido, articuladas ambas por el concepto de phúsis.

[55] Cf. Ibíd, p.410.

THÉMATA. Revista de Filosofía, No 51 enero-junio (2015) pp.: 363-382 doi: 10.12795/themata.2015.i51.19 


\section{Referencias bibliográficas:}

Agamben, G. Homo Sacer: el poder soberano y la nuda vida, I, Ed. Pre-textos, Valencia, 1998.

Escudero, J.A, El lenguaje de Heidegger, diccionario filosófico 19121927, Herder, Barcelona, 2009.

Deleuze, Nietzsche y la filosofía, Anagrama, 1998.

Derrida, J., Políticas de la amistad, seguido del oído de Heidegger, Trotta, Madrid, 1998.

Faye, E., La introducción del nazismo en la filosofía, Akal, 2009.

Heidegger, M. El ser y el tiempo, Fondo de Cultura Económica, Méjico, 1999.

Ser y Tiempo, Ed. Trotta, Madrid, 2009.

"Ciencia y Meditación" en Conferencias y artículos, Ediciones del Serbal, Barcelona, 2001.

"Sobre la esencia y el concepto de la phúsis. Aristóteles, Física B. I" en, Hitos [Wegmarken], Ed. Alizanza, Madrid, 2000.

"El final de la filosofía y la tarea del pensar", en VV.AA, Kierkegaard vivo, Alianza, Madrid, 1968.

"El final de la filosofía y la tarea del pensar" Tiempo y Ser, Tecnos, Madrid, 2000.

Identidad y diferencia, Anthropós, Barcelona, 1988.

Gelassenheit, Ediciones del Serbal, Barcelona, 1994.

"La pregunta por la técnica" en Conferencias y artículos, Ediciones del Serbal, Barcelona 1994.

Kaufmann, M. ¿Derecho sin reglas? Los principios filosóficos de la teoría del Estado y del derecho en Carl Schmitt, Ed. Alfa, Caracas/Barcelona, 1989.

Peñalver, P., "Decisiones, Schmitt, Heidegger, Barth", Daimon, 13, 1996, pgs. 141-166.

Pöggeler, O., El camino del pensar de Martin Heidegger, Alianza Editorial, Madrid, 1993.

Sáez Rueda. L., Movimientos filosóficos actuales, Ed. Trotta, Madrid, 2001.

Sloterdijk, P., Normas para el parque humano, Siruela, Madrid, 2000.

Schmitt, C. El nomos de la tierra en el Derecho de Gentes del "Ius publicum europaeum”, Ed. Comares, Granada, 2002.

Tierra y mar, Ed. Trotta, Madrid, 2009

"La era de las neutralizaciones y las despolitizaciones" en El concepto 
de lo político, Alianza Editorial, Madrid, 2009

Der Begriff des Politischen (1927), $2^{\mathrm{a}}$ ed. (Hamburg: Hanseatische Verlagsanstalt, 1934)

Römischer Katholizismus und politische Form, Gottasche Buchlandlung Nadifolger GmbH, Sutgart, 1923, (Catolicismo romano y forma política, Tr. Campderrich Bravo, R., Tecnos, Madrid, 2011).

Villacañas, J.L., Poder y conflicto, ensayos sobre Carl Schmitt, Biblioteca Nueva, Madrid, 2008.

Volpi, F, "El poder de los elementos" en Tierra y Mar, una reflexión sobre la historia universal, Trotta, Madrid, 2007. 